\title{
PENERAPAN SCAFFOLDING SEBAGAI UPAYA DALAM MENINGKATKAN LEVEL BERPIKIR MATEMATIS SISWA DITINJAU DARI TAKSONOMI SOLO
}

\author{
Rudy Setiawan', Zuni Mitasari \\ ${ }^{1,2}$ Universitas Tribhuwana Tunggadewi \\ rudiehabibi@gmail.com ${ }^{1}$,zmitasari@gmail.com²
}

Received 10 May 2020; revised 23 June 2020; accepted 28 June 2020.

\begin{abstract}
ABSTRAK
Tujuan penelitian ini yaitu adanya peningkatan level berpikir matematis siswa berdasarkan taksonomi SOLO yang diberikan bantuan scaffolding pada materi pertidaksamaan linier. Objek penelitian ini adalah siswa kelas VIII SMP Tazkia IIBS Malang yang sudah pernah mempelajari materi pertidaksamaan linier. Penelitian ini merupakan penelitian kualitatifdeskriptif-responsif dengan jenis penelitian studi kasus. Jumlah objek penelitian sebanyak 3 siswa dengan rincian 1 siswa dengan level berpikir aljabar unistructural (level 1), 1 siswa dengan level berpikir aljabar multistructural (level 2), dan 1 siswa dengan level berpikir aljabar relational (level 3). Penelitian ini melibatkan scaffolding sebagai perlaukan utama untuk meningkatkan level berpikir matematis siswa. Berdasarkan hasil penelitian ditemukan bahwa setelah pemberian scaffolding pada tes tertulis 1, dari siswa dengan level berpikir aljabar unistructural (level 1) dapat meningkat menjadi multistructural (level 2). Siswa dengan level berpikir aljabar multistructural (level 2) dapat meningkat menjadi extended abstract (level 4). Serta siswa dengan level berpikir aljabar relational (level 3) dapat meningkat menjadi extended abstract (level 4).
\end{abstract}

Kata kunci: aljabar, level berpikir matematis, taksonomi SOLO, scaffolding.

\begin{abstract}
The purpose of this research is to increase students' level of algebraic thinking based on SOLO model in linier equation material and moreover raise students' level of mathematics thinking by giving scaffolding to students. This research was done to the eighth grade students of Taskia IIBS Malang Junior High School who have already learnt about linier unequation. This research about qualitative descriptive on case study. Three students were choosen as the objects of the research with the specification that one students as anunistructural level of mathematics (algebraic) thinking (as level 1), other one students asmultistructural level of mathematics (algebraic) thinking (as level 2), and one students had relational level of algebraic thinking (as
\end{abstract}


level 3). Theobtain of this research, explained about the finding of students' levels of mathematics (algebraic) thinking were increased in written test 1by giving scaffolding. One of students asunistructural level of mathematics (algebraic) thinking (level 1) could be increasing tomultistructural level (level 2). Other one studentsonmultistructural level of mathematics (algebraic) could increase into extended abstract level. Finally, the last students on relational level of mathematics (algebraic) could increase his level into extended abstract level.

Keywords: algebra, level of mathematics thinking, SOLO taxonomy, scaffolding.

\section{PENDAHULUAN}

Penalaran matematis siswa adalah hal yang mutlak harus dimiliki oleh setiap siswa pada saat ini (Arifendi \& Setiawan, 2019). Pada saat ini, salah satu materi dalam matematika yang penting untuk dipelajari adalah aljabar. Aljabar juga merupakan salah satu topik penting yang diajarkan di kelas VIII. Bingolbali dkk (2010) mengemukakan bahwa siswa di tiap tingkatan pasti pernah mendapatkan kesulitan ketika belajar matematika, dan salah satu materi yang dirasa sulit oleh siswa pada tingkat menengah adalah aljabar. Siswa diharuskan memiliki pemahaman aljabar sebab materi aljabar memiliki peranan penting bagi siswa. Pendidik sebenarnya telah mengetahui tentang berpikir sebagai suatu media guna mendapatkan pemahaman terhadap suatu materi, atau dalam menyelesaikan masalah dengan jelas (Wongyai \& Kamol, 2003). Oleh karena itu, menjadi penting bagi pendidik untuk memiliki kemampuan mengembangkan cara berpikir matematis siswa, terutama berpikir terhadap materi aljabar. Tujuannya adalah agar siswa dapat meningkat pemahaman terhadap materi tersebut.

Teori kognitif yang membahas tentang level berpikir siswa adalah teori kognitif taksonomi SOLO (Structure of Observed Learning Outcome). Menurut Lian \& Idris (2006), taksonomi SOLO mengklasifikasikan level berpikir matematis siswa meliputi 4 tingkatan yaitu (1) unistruktural (unistructural), (2) multistruktural (multistructural), (3) relasional (relational), dan (4) abstrak yang diperluas (extended abstract). Lian \& Idris (2006) mengatakan bahwa taksonomi SOLO adalah model psikologi kognitif yang lebih menekankan pada investigasi dan proses internal siswa dalam menyelesaikan masalah daripada jawaban benar siswa. Hal ini senada dengan Setiawan dan Arifendi (2017) yang menyatakan bahwa kreativitas matematika peserta didik berdasarkan pemahaman aljabarnya. 
Masalah tentang aljabar yang digunakan pada penelitian ini meliputi pertidaksamaan linier yang dipelajari oleh kelas VIII. Hasil observasi awal yang dilakukan di SMP Tazkia IIBS Malang di kelas VIII-B tahun ajaran 2018/2019, diperoleh fakta bahwa dari 30 siswa, 17 siswa berada pada level 1 (level unistruktural), 9 siswa berada pada level 2 (level multistruktural), 3 siswa pada level 3 (level aljabar relasional), dan satu siswa pada level 4 (level abstrak diperluas). Jadi, peningkatan level berpikir aljabar siswa perlu diwujudkan agar siswa mampu menyelesaikan masalah matematika (aljabar) baik masalah lama maupun masalah dalam situasi terbaru. Level berpikir aljabar siswa dapat ditingkatkan, dengan menggunakan scaffolding. Sesuai dengan pendapat dari Sujiati (2011) bahwa proses dalam berpikir siswa ketika penyelesaian masalah bersifat unik, dan umumnya proses dalam berpikir setiap siswa dapat dikembangkan melalui pemberian scaffolding. Penerapan scaffolding bertujuan untuk mendeskripsikan dukungan terhadap proses yang memberikan kemungkinan terhadap siswa dalam penyelesaian masalah, mengerjakan tugas atau mencapai tujuannya (Kolikant \& Broza, 2011). Sujiati (2011) di dalam penelitiannya menyebutkan adanya 3 level dalam scaffolding yang meliputi (1) scaffolding level 1 (environmental provisions) sebagai contoh yaitu pemanfaatan media pembelajaran didalam kelas, (2) scaffolding level 2 (explaining, reviewing, and restructuring) sebagai contoh menjelaskan kepada siswa atau melemparkan pertanyaan pancingan/arahan, dan (3) scaffolding level 3 (developing conceptual thinking) sebagai contoh yaitu kegiatan diskusi bersama siswa.

Scaffolding yang diterapkan dalam penelitian ini merupakan bantuan secukupnya dari peneliti terhadap siswa yang berpikir secara matematis (aljabar) level 1 sampai level 3 berdasarkan taksonomi SOLO. Scaffolding dalam penelitian ini berupa interaksi antara siswa dan peneliti, dengan kata lain pemanfaatan scaffolding dalam penelitian ini meliputi scaffolding level 2 dan scaffolding level 3.

\section{METODE PENELITIAN}

Penelitian ini adalah kualitatif-deskriptif-eksploratif yang berjenis studi kasus. Adapun penelitian ini mendeskripsikan level berpikir aljabar siswa pada 
saat melakukan penyelesaian masalah pertidaksamaan linier dan pemberian scaffolding untuk meningkatkan level berpikir aljabar siswa. Selain itu, penelitian ini juga merupakan penelitian tindakan partisipan. Hal ini dikarenakan, tidak hanya mendeskripsikan level berpikir aljabar siswa, namun juga memberikan tindakan untuk meningkatkan level berpikir matematis siswa pada materi pertidaksamaan linier.

Tahapan penelitian ini ada 3 tahap, yaitu: (1) studi pendahuluan, (2) perencanaan, dan (3) pelaksanaan tindakan. Penelitian dilaksanakan di SMP Tazkia IIBS Malang pada semester genap. Subjek penelitian dipilih tiga orang siswa kelas VIII-B yang sudah mempelajari konsep pertidaksamaan linier; satu orang siswa pada level 1, satu orang siswa level 2, dan satu orang siswa pada level 3. Penentuan subjek penelitian didasarkan pada hasil kerja siswa pada saat tes observasi awal.

Penelitian ini merupakan penelitian kualitatif yang didukung dengan penggunaan dua kali lembar tes tulis. Penyusunan lembar tes berdasarkan pada superitem test model taksonomi SOLO. Lian \& Idris (2006) menyatakan superitem test merupakan alat asesmen kuat yang dapat mengukur kemampuan kognitif siswa dalam menyelesaikan masalah matematika. Superitem memuat suatu masalah dan empat level kesulitan yang berbeda. Representasi dari item tersebut mencakup empat level pada taksonomi SOLO yaitu level unistruktural, level multistruktural, level relational, dan level abstrak diperluas.

\section{HASIL PENELITIAN DAN PEMBAHASAN}

Deskripsi level berpikir matematis (aljabar) siswa berdasarkan Taksonomi SOLO pada materi pertidaksamaan linier dan pemberian scaffolding yang didapatkan dalam penelitian ini berperan dalammeningkatkan level berpikir aljabar siswa. Dalam pemilihan subjek penelitian, peneliti memberikan tes tertulis 1 kepada seluruh siswa kelas VIII-B SMP Tazkia IIBS Malang. Pemilihan kelas VIII-B merupakan masukan dari guru mata pelajaran matematika SMP Taskia IIBS Malang, karena peneliti juga berperan sebagai guru rekanan dalam pengajar persiapan Olimpiade Matematika. Hasil pekerjaan siswa terhadap tes tertulis 1 dikaji peneliti untuk menentukan level berpikir aljabar dari masing-masing siswa. 
Dipilih 3 subjek yaitu 1 siswa dengan kemampuan berpikir aljabar level 1 selanjutnya disebut S1, 1 siswa dengan kemampuan berpikir aljabar level 2 selanjutnya disebut $\mathbf{S} 2$ dan 1 siswa dengan kemampuan berpikir aljabar level 3 selanjutnya disebut S3. Subjek-subjek yang dipilih seperti pada Gambar 1.

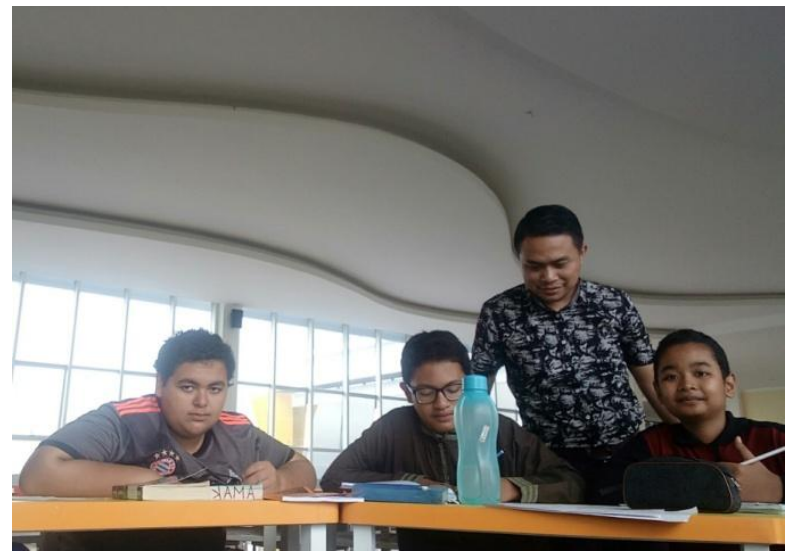

Gambar 1. Suasana Penelitian antara Peneliti Bersama Siswa S1, S2, dan S3

Level berpikir aljabar masing-masing subjek dipaparkan untuk masalah mengenai pertidaksamaan linier Deskripsi level berpikir aljabar masing-masing siswa disajikan baik sebelum maupun sesudah scaffolding dari peneliti. Selanjutnya, level berpikir aljabar siswa setelah mengerjakan tes tertulis 2 dikaji apakah mengalami peningkatan atau belum.

\section{Deskripsi Level Berpikir Matematis (Aljabar) S1 Berdasarkan Taksonomi SOLO Melalui Pemberian Scaffolding}

Rincian hasil pekerjaan S1 dalam menyelesaikan masalah tes tertulis 1 dan pemberian scaffolding oleh peneliti kepada S1 seperti pada Tabel 1.

Tabel 1. Deskripsi Level Berpikir Matematis (Aljabar) S1 Berdasarkan Taksonomi SOLO Melalui Pemberian Scaffolding

\begin{tabular}{|c|c|c|c|c|}
\hline Pertanyaan & $\begin{array}{c}\text { Deskripsi } \\
\text { Pekerjaan S1 }\end{array}$ & $\begin{array}{c}\text { Masalah yang } \\
\text { dihadapi S1 }\end{array}$ & $\begin{array}{c}\text { Bentuk } \\
\text { scaffolding yang } \\
\text { diberikan }\end{array}$ & \begin{tabular}{l}
\multicolumn{1}{c}{ Jenis } \\
komponen \\
scaffolding
\end{tabular} \\
\hline Level 1 & $\begin{array}{l}\text { S1 menjawab } \\
\text { dengan benar }\end{array}$ & - & - & - \\
\hline Level 2 & $\begin{array}{l}\text { Jawaban yang } \\
\text { diberikan S1 } \\
\text { salah }\end{array}$ & $\begin{array}{l}\text { S1 melakukan } \\
\text { kesalahan } \\
\text { menentukan } \\
\text { cara/ strategi } \\
\text { dalam } \\
\text { menyelesaikan }\end{array}$ & $\begin{array}{l}\text { Peneliti meminta } \\
\text { S1 untuk } \\
\text { menjelaskan } \\
\text { strateginya dalam } \\
\text { menyelesaikanma } \\
\text { salah sehingga }\end{array}$ & $\begin{array}{l}\text { Reviewing: } \\
\text { student } \\
\text { explaining } \\
\text { and } \\
\text { justifying }\end{array}$ \\
\hline
\end{tabular}




\begin{tabular}{|c|c|c|c|c|}
\hline Pertanyaan & $\begin{array}{c}\text { Deskripsi } \\
\text { Pekerjaan S1 }\end{array}$ & $\begin{array}{l}\text { Masalah yang } \\
\text { dihadapi S1 }\end{array}$ & $\begin{array}{c}\text { Bentuk } \\
\text { scaffolding yang } \\
\text { diberikan }\end{array}$ & $\begin{array}{c}\text { Jenis } \\
\text { komponen } \\
\text { scaffolding }\end{array}$ \\
\hline \multirow[b]{2}{*}{$\begin{array}{l}\text { Level } 3 \\
\text { pertanyaan } \\
\text { pertama }\end{array}$} & \multirow[b]{2}{*}{$\begin{array}{l}\text { S1 tidak } \\
\text { menjawab }\end{array}$} & masalah & $\begin{array}{l}\text { peneliti dapat } \\
\text { membenarkan } \\
\text { cara siswa yang } \\
\text { salah }\end{array}$ & \\
\hline & & $\begin{array}{l}\text { - } \mathrm{S} 1 \text { belum } \\
\text { memahami } \\
\text { makna } \\
\text { variabel y } \\
\text { pada } \\
\text { pertanyaan } \\
\text { ini }\end{array}$ & $\begin{array}{l}\text { Peneliti } \\
\text { memberikan } \\
\text { pertanyaan } \\
\text { arahan hingga } \mathrm{S} 1 \\
\text { dapat memahami } \\
\text { makna variabel } \\
\text { dan membimbing } \\
\text { S1 menyelesaikan } \\
\text { masalah }\end{array}$ & $\begin{array}{l}\text { Reviewing: } \\
\text { prompting } \\
\text { question }\end{array}$ \\
\hline \multirow[t]{2}{*}{$\begin{array}{l}\text { Level } 3 \\
\text { pertanyaan } \\
\text { ke-dua }\end{array}$} & $\begin{array}{l}\text { S1 tidak } \\
\text { menjawab }\end{array}$ & $\begin{array}{l}\text { S1 tidak } \\
\text { memahami apa } \\
\text { yang dimaksud } \\
\text { pertidaksamaan } \\
\text { linier }\end{array}$ & $\begin{array}{l}\text { Peneliti } \\
\text { memberikan } \\
\text { contoh } \\
\text { pertidaksamaan } \\
\text { linier dua variabel } \\
\text { dan meminta S1 } \\
\text { untuk } \\
\text { mengidentifikasi } \\
\text { ciri-ciri } \\
\text { pertidaksamaan } \\
\text { linier }\end{array}$ & $\begin{array}{l}\text { Explaining: } \\
\text { showing } \\
\text { and telling }\end{array}$ \\
\hline & & $\begin{array}{l}\text { S1 tidak } \\
\text { memahami } \\
\text { makna variabel } t \\
\text { dan } p \text { pada soal }\end{array}$ & $\begin{array}{l}\text { Peneliti meminta } \\
\text { S1 untuk } \\
\text { membaca ulang } \\
\text { soal level } 3 \text { yang } \\
\text { pertama dan } \\
\text { memahami } \\
\text { perbedaan } \\
\text { variabel yang } \\
\text { digunakan antara } \\
\text { soal yang pertama } \\
\text { dan kedua }\end{array}$ & $\begin{array}{l}\text { Reviewing: } \\
\text { looking, } \\
\text { touching, } \\
\text { and } \\
\text { verbalizing }\end{array}$ \\
\hline $\begin{array}{l}\text { Level } 3 \\
\text { pertanyaan } \\
\text { ke-tiga }\end{array}$ & $\begin{array}{l}\text { Hasil } \\
\text { pekerjaan } \\
\text { terhadap tes } \\
\text { tertulis } 1, \mathrm{~S} 1 \\
\text { tidakmenjawab } \\
\text { pertanyaan ini. } \\
\text { Namun setelah } \\
\text { pemberian } \\
\text { scaffolding } \\
\text { pada }\end{array}$ & - & - & - \\
\hline
\end{tabular}




\begin{tabular}{|c|c|c|c|c|}
\hline Pertanyaan & $\begin{array}{c}\text { Deskripsi } \\
\text { Pekerjaan S1 }\end{array}$ & $\begin{array}{c}\text { Masalah yang } \\
\text { dihadapi S1 }\end{array}$ & $\begin{array}{c}\text { Bentuk } \\
\text { scaffolding yang } \\
\text { diberikan }\end{array}$ & $\begin{array}{c}\text { Jenis } \\
\text { komponen } \\
\text { scaffolding }\end{array}$ \\
\hline Level 4 & $\begin{array}{l}\text { pertanyaan } \\
\text { sebelumnya, } \\
\text { S1 dengan } \\
\text { mudahm } \\
\text { enyelesaikan } \\
\text { masalah ini } \\
\text { S1 tidak } \\
\text { menjawab }\end{array}$ & $\begin{array}{l}\text { S1 tidak } \\
\text { memahami } \\
\text { maksud soal }\end{array}$ & $\begin{array}{l}\text { Peneliti meminta } \\
\text { S1 membaca } \\
\text { ulang masalah } \\
\text { kemudian } \\
\text { mengajak S1 } \\
\text { berdiskusi } \\
\text { mengenai cara } \\
\text { atau alternatif lain } \\
\text { untuk } \\
\text { menyelesaikan } \\
\text { masalah }\end{array}$ & $\begin{array}{l}\text { Developing } \\
\text { conceptual } \\
\text { thinking: } \\
\text { generating } \\
\text { conceptual } \\
\text { discourse }\end{array}$ \\
\hline
\end{tabular}

Hasil pekerjaan S1 terhadap tes tertulis 1 menunjukkan bahwa S1 dapat menjawab dengan benar pertanyaan level 1. S1 dikatakan memiliki kemampuan berpikir aljabar level 1 berdasarkan taksonomi SOLO yang disebut unistructural.

\section{Peningkatan Level Berpikir Matematis (Aljabar) S1 BerdasarkanTaksonomi SOLO Setelah Pemberian Scaffolding}

Peneliti telah memberikan scaffolding kepada S1 seperti pada Tabel 1 dalam menyelesaikan semua masalah pada tes tertulis 1. Untuk selanjutnya, peneliti memberikan tes tertulis 2 kepada S1 untuk mengetahui apakah S1 mengalami peningkatan level berpikir aljabar berdasarkan taksonomi SOLO setelah pemberian scaffolding. Berdasarkan hasil tes tertulis 2 yang dikerjakan S1, S1 dapat menjawab dengan benar soal level 1, level 2, dan level 3. S1 dikatakan memiliki kemampuan berpikir aljabar level 3 berdasarkan taksonomi SOLO. Hal tersebut memaparkan akibat setelah mendapatkan scaffolding, S1 mengalami peningkatan berpikir aljabar berdasarkan taksonomi SOLO dari level 1 menjadi level 3. 


\section{Deskripsi Level Berpikir Matematis (Aljabar) S2 Berdasarkan Taksonomi SOLO Melalui Pemberian Scaffolding}

Rincian hasil pekerjaan S2 dalam menyelesaikan masalah tes tertulis 1 dan pemberian scaffolding oleh peneliti kepada S2 diberikan pada Tabel 2.

Tabel 2 Deskripsi Level Berpikir Matematis (Aljabar) S2 Berdasarkan Taksonomi SOLO Melalui Pemberian Scaffolding

\begin{tabular}{|c|c|c|c|c|}
\hline Pertanyaan & $\begin{array}{c}\text { Deskripsi } \\
\text { Pekerjaan S2 }\end{array}$ & $\begin{array}{c}\text { Masalah yang } \\
\text { dihadapi S2 }\end{array}$ & $\begin{array}{c}\text { Bentuk } \\
\text { scaffolding yang } \\
\text { diberikan }\end{array}$ & $\begin{array}{c}\text { Jenis } \\
\text { komponen } \\
\text { scaffolding } \\
\end{array}$ \\
\hline Level 1 & $\begin{array}{l}\text { S2 menjawab } \\
\text { dengan benar }\end{array}$ & - & - & - \\
\hline Level 2 & $\begin{array}{l}\text { S2 menjawab } \\
\text { dengan benar. }\end{array}$ & - & - & - \\
\hline $\begin{array}{l}\text { Level } 3 \\
\text { pertanyaan } \\
\text { pertama }\end{array}$ & $\begin{array}{l}\text { Jawaban S2 } \\
\text { salah }\end{array}$ & $\begin{array}{l}\text { S2 tidak } \\
\text { memahami } \\
\text { makna soal }\end{array}$ & $\begin{array}{l}\text { Peneliti } \\
\text { mengajukan } \\
\text { pertanyaan arahan } \\
\text { agar S2 dapat } \\
\text { memahami soal } \\
\text { dan membimbing } \\
\text { S2 menyelesaikan } \\
\text { masalah dengan } \\
\text { benar }\end{array}$ & $\begin{array}{l}\text { Reviewing: } \\
\text { prompting } \\
\text { question }\end{array}$ \\
\hline $\begin{array}{l}\text { Level } 3 \\
\text { pertanyaan } \\
\text { ke-dua }\end{array}$ & $\begin{array}{l}\text { Dari hasil } \\
\text { pekerjaan S2 } \\
\text { pada tes } \\
\text { tertulis 1, S2 } \\
\text { tidak } \\
\text { menjawab } \\
\text { pertanyaan ini. } \\
\text { Setelah } \\
\text { pemberian } \\
\text { scaffolding } \\
\text { pada } \\
\text { pertanyaan } \\
\text { sebelumnya, } \\
\text { S2 menjawab } \\
\text { pertanyaan } \\
\text { jawaban } \\
\text { tersebut masih } \\
\text { salah }\end{array}$ & $\begin{array}{l}\text { S2 terlalu } \\
\text { tergesa-gesa } \\
\text { dalam } \\
\text { menjawab dan } \\
\text { tidak teliti }\end{array}$ & $\begin{array}{l}\text { Peneliti meminta } \\
\text { S2 memeriksa } \\
\text { kembali jawaban } \\
\text { yang telah } \\
\text { dibuatnya } \\
\text { sehingga dapat } \\
\text { menemukan } \\
\text { kesalahan }\end{array}$ & $\begin{array}{l}\text { Reviewing: } \\
\text { interpreting } \\
\text { looking, } \\
\text { touching, } \\
\text { and } \\
\text { verbalizing }\end{array}$ \\
\hline $\begin{array}{l}\text { Level } 3 \\
\text { pertanyaan } \\
\text { ke-tiga }\end{array}$ & $\begin{array}{l}\text { Berdasarkan } \\
\text { hasil pekerjaan } \\
\text { S2 pada tes } \\
\text { tertulis } 1, \mathrm{~S} 2 \\
\text { tidak } \\
\text { menjawab }\end{array}$ & - & - & - \\
\hline
\end{tabular}




\begin{tabular}{|c|c|c|c|c|}
\hline Pertanyaan & $\begin{array}{c}\text { Deskripsi } \\
\text { Pekerjaan S2 }\end{array}$ & $\begin{array}{c}\text { Masalah yang } \\
\text { dihadapi S2 }\end{array}$ & $\begin{array}{c}\text { Bentuk } \\
\text { scaffolding yang } \\
\text { diberikan }\end{array}$ & $\begin{array}{c}\text { Jenis } \\
\text { komponen } \\
\text { scaffolding }\end{array}$ \\
\hline Level 4 & $\begin{array}{l}\text { pertanyaan ini. } \\
\text { Setelah } \\
\text { pemberian } \\
\text { scaffolding } \\
\text { pada } \\
\text { pertanyaan } \\
\text { sebelumnya S2 } \\
\text { dapat } \\
\text { menyelesaikan } \\
\text { pertanyaan ini } \\
\text { dengan benar } \\
\text { Jawaban S2 } \\
\text { salah }\end{array}$ & $\begin{array}{l}\text { S2 belum } \\
\text { memahami } \\
\text { maksud soal }\end{array}$ & $\begin{array}{l}\text { Peneliti } \\
\text { memberikan } \\
\text { pertanyaan arahan } \\
\text { kepada S2 } \\
\text { sehingga S2 } \\
\text { memahami } \\
\text { maksud soal. } \\
\text { Peneliti berdiskusi } \\
\text { dengan S2 dalam } \\
\text { mencari alternatif } \\
\text { atau cara lain } \\
\text { dalam } \\
\text { menyelesaikan } \\
\text { masalah. }\end{array}$ & $\begin{array}{l}\text { Reviewing: } \\
\text { prompting } \\
\text { question. } \\
\text { Developing } \\
\text { conceptual } \\
\text { thinking: } \\
\text { generating } \\
\text { conceptual } \\
\text { discourse } \\
\text { Explaining: } \\
\text { showing } \\
\text { and telling }\end{array}$ \\
\hline
\end{tabular}

Peneliti telah memberikan scaffolding kepada S3 seperti pada bagian 3 dalam menyelesaikan semua masalah pada tes tertulis 1 . Untuk selanjutnya, peneliti memberikan tes tertulis 2 kepada S2 untuk mengetahui apakah S3 mengalami peningkatan level berpikir aljabar berdasarkan taksonomi SOLO setelah pemberian scaffolding. Berdasarkan hasil tes tertulis 2 yang dikerjakan S2 pada Tabel 2, S2 dapat menjawab dengan benar soal level 1 sampai dengan level 4. S2 dikatakan memiliki kemampuan berpikir aljabar level 4 berdasarkan taksonomi SOLO. Hal tersebut menunjukkan bahwa setelah mendapatkan scaffolding, S2 mengalami peningkatan berpikir aljabar berdasarkan taksonomi SOLO dari level 2 menjadi level 4. 
Deskripsi Level Berpikir Matematis (Aljabar) S3 Berdasarkan Taksonomi SOLO Melalui Pemberian Scaffolding

Rincian hasil pekerjaan S3 dalam menyelesaikan masalah tes tertulis 1 dan pemberian scaffolding oleh peneliti kepada S3 diberikan pada Tabel 3.

Tabel 3 Deskripsi Level Berpikir Matematis (Aljabar) S3 Berdasarkan Taksonomi SOLO Melalui Pemberian Scaffolding

\begin{tabular}{|c|c|c|c|c|}
\hline Pertanyaan & $\begin{array}{c}\text { Deskripsi } \\
\text { Pekerjaan S3 }\end{array}$ & $\begin{array}{c}\text { Masalah yang } \\
\text { dihadapi S3 }\end{array}$ & $\begin{array}{c}\text { Bentuk } \\
\begin{array}{c}\text { scaffolding yang } \\
\text { diberikan }\end{array} \\
\end{array}$ & $\begin{array}{c}\text { Jenis } \\
\text { komponen } \\
\text { scaffolding } \\
\end{array}$ \\
\hline Level 1 & $\begin{array}{l}\text { S3 menjawab } \\
\text { dengan benar }\end{array}$ & - & - & - \\
\hline Level 2 & $\begin{array}{l}\text { S3 menjawab } \\
\text { dengan benar. }\end{array}$ & - & - & - \\
\hline $\begin{array}{l}\text { Level } 3 \\
\text { pertanyaan } \\
\text { pertama }\end{array}$ & $\begin{array}{l}\text { S3 menjawab } \\
\text { dengan benar }\end{array}$ & - & - & - \\
\hline $\begin{array}{l}\text { Level } 3 \\
\text { pertanyaan } \\
\text { ke-dua }\end{array}$ & $\begin{array}{l}\text { S3 menjawab } \\
\text { dengan benar }\end{array}$ & - & - & - \\
\hline $\begin{array}{l}\text { Level } 3 \\
\text { pertanyaan } \\
\text { ke-tiga }\end{array}$ & $\begin{array}{l}\text { S3 menjawab } \\
\text { pertanyaan } \\
\text { ketiga }\end{array}$ & - & - & - \\
\hline Level 4 & $\begin{array}{l}\text { Jawaban S3 } \\
\text { salah. S3 tidak } \\
\text { dapat } \\
\text { menjelaskan } \\
\text { maksud } \\
\text { jawaban yang } \\
\text { diatuliskan }\end{array}$ & $\begin{array}{l}\text { S3 belum } \\
\text { memahami } \\
\text { maksud soal }\end{array}$ & $\begin{array}{l}\text { Peneliti } \\
\text { menyelesaikan } \\
\text { masalah dengan } \\
\text { penyelesaian yang } \\
\text { memiliki } \\
\text { karakteristik mirip } \\
\text { dengan masalah } \\
\text { original kemudian } \\
\text { meminta S3 untuk } \\
\text { mengomentari } \\
\text { penyelesaian } \\
\text { tersebut. } \\
\text { Selanjutnya } \\
\text { menuntun S3 } \\
\text { menyelesaikan } \\
\text { masalah level } 4 \\
\text { dengan benar. }\end{array}$ & $\begin{array}{l}\text { Reviewing: } \\
\text { parallel } \\
\text { modelling }\end{array}$ \\
\hline
\end{tabular}




\section{Peningkatan Level Berpikir Matematis (Aljabar) S3 Berdasarkan}

\section{Taksonomi SOLO Setelah Pemberian Scaffolding}

Peneliti telah memberikan scaffolding, berdasarkan hal tersebut menunjukkan bahwa setelah mendapatkan scaffolding, S3 mengalami peningkatan berpikir aljabar berdasarkan taksonomi SOLO dari level 3 menjadi level 4.

\section{SIMPULAN}

Siswa dengan kemampuan berpikir matematis (aljabar) level 1 (unistructural) pada saat penyelesaian masalah aljabar berdasarkan taksonomi SOLO hanya berfokus terhadap satu informasi yang relevan terhadap masalah yang diberikan. Tujuannya untuk memberikan respon terhadap masalah tersebut, jawaban siswa berasal dari satu informasi pada masalah yang diberikan. Siswa dengan kemampuan berpikir matematis (aljabar) level 2 (multistructural) dalam menyelesaikan masalah aljabar berdasarkan taksonomi SOLO berfokus pada beberapa informasi yang relevan pada masalah yang diberikan untuk memberikan respon terhadap masalah tersebut tetapi informasi-informasi ini masih diperlakukan dengan bebas atau tidak terintegrasi. Siswa dengan kemampuan berpikir matematis (aljabar) level 3 (relational) dalam menyelesaikan masalah aljabar berdasarkan taksonomi SOLO siswa mengintegrasikan semua aspek informasi yang diberikan satu sama lain menjadi struktur yang koheren. Tindakan scaffolding yang tepat pada siswa dengan level berpikir aljabar unistructural, multistructural, dan relational dapat meningkatkan level berpikir matematis (aljabar) pada siswa. Hal tersebut dibuktikan pada hasil penelitian yang telah dipaparkan.

\section{DAFTAR PUSTAKA}

Arifendi, R. F., \& Setiawan, R. (2019). Upaya peningkatan penalaran matematis mahasiswa universitas tribhuwana tunggadewi melalui pendekatan cotextual teaching learning (CTL). Jurnal Prismatika,1(2), 55-59. https://doi.org/10.33503/prismatika.v1i2.435.

Bingolbali, E., Akkoç, H., Ozmantar, M. F., \& Demir, S. (2010). Pre-service and in-service teachers "views of the sources of students"e mathematical difficulties. International Electronic Journal of Mathematics Education, $6(1), 41-59$. 
Kolikant, Y. B. D., \& Broza, O. (2011). The effect of using a video clip presenting a contextual story on low-achieving students' mathematical discourse. Educational studies in mathematics, 76(1), 23-47. http://doi.org/10.1007/s10649-010-9262-5

Lian, L. H., \& Idris, N. (2006). Assessing algebraic solving ability of form four students. International Electronic Journal of Mathematics Education, 1(1), 55-76.

Setiawan, R., \& Arifendi, R. F. (2017). Alternatif peningkatan kreativitas mahasiswa universitas tribhuwana tunggadewi melalui pohon matematika. MUST: Journal of Mathematics, Education, Science and Technology, 2(2) 189-195. http://doi.org/10.30651/must.v2i2.779.

Sujiati, A. (2011). Proses berpikir siswa dalam pemecahan masalah dengan pemberian scaffolding. Tesis tidak diterbitkan. Malang: Program Pascasarjana Universitas Negeri Malang.

Wongyai, P., \& Kamol, N. (2003). A framework in characterizing lower secondary school students' algebraic thinking. Bangkok: Srinakharinwirot University. 